\title{
Concern over dental regulator's covert investigations
}

Dental Protection has said it is disappointed and concerned that the General Dental Council (GDC) is engaging in undercover investigations which are attempting to trick dentists into wrong-doing.

Dental Protection's concern stems from a 2016 case where it defended a dental technician who was the subject of an anonymous complaint to the GDC that he may be working without registration, due to his laboratory being in a bespoke setting in his home. Two months later the GDC instructed an under-guise operation where two private investigators attended an appointment posing as relatives of an elderly lady Evelyn' who needed new partial dentures but was very ill and could not attend in person.

The fictitious scenario unfairly attempted to lure the dental technician into doing something against his better judgement on compassionate grounds - but the investigation was also far removed from the original complaint which was about registration.
An Interim Orders Committee concluded that any evidence from the investigation was flawed and unfair, and the GDC Practice Committee halted any further action on grounds that the investigation demonstrated abuse of process. Dental Protection, alongside legal firm BLM, also sought an order against the GDC to recover legal costs, which the GDC conceded in August.

The number of covert investigations undertaken by the GDC has not been established, but a Freedom of Information (FOI) request revealed that it spent a minimum of $£ 15,416$ in 2017 alone.

Raj Rattan, Dental Director at Dental Protection, said: 'The fact that the GDC is prepared to target its own registrants without a sufficiently justified cause is, in itself, unsettling for dentists. But what I find most concerning and disappointing is the covert nature of the investigation.

'The use of an entirely contrived scenario about a sick pensioner in very difficult circumstances was designed to trigger an emotional response and lure a registrant into acting outside of their scope. This is hardly an ordinary opportunity for wrongdoing, and it is unfair and invasive.

'While the GDC has declined to share information on its use of covert investigations, we do know from an FOI request that it spent a sizeable amount of its registrants' fees - over $£ 15 \mathrm{~K}$ - on undercover investigations in 2017.

Furthermore, throughout the case discussed the GDC asserted that under-guise investigations are essential to carry out its statutory function.'

Commenting on the news, British Dental Association Chair Mick Armstrong said: 'When illegal tooth whitening is running rampant, and braces are being flogged via websites, the GDC should be using tactics like mystery shoppers to protect patients.

'Entrapment is entirely another matter. These sort of Stasi tactics are not a good look for a professional regulator that lists its values as 'fairness, transparency, responsiveness and respect.'

\section{FOl reveals 48 'breaches of DOH regulations'}

As many as 1.9 million courses of dental treatment carried out in England over the last 12 months may have taken place at clinics that breach strict guidelines on health, safety and welfare.

A Freedom of Information request obtained the results of inspections carried out by the Care Quality Commission (CQC), the healthcare regulator.

Analysis reveals that of the 1,067 dentists inspected by the CQC last year, 48 were found to be in breach of the strict Department of Health regulations covering infection control to maintain people's health, safety and welfare and also the suitability and safety of premises dental treatments take place in. The NHS England reports that 39.7 million courses of treatment were delivered in 2018/19.

The results are of little surprise to dentist Miguel Stanley, founder of the Slow Dentistry movement.

'As dentists we all want to deliver the best quality patient care. However, as the results of the CQC inspections have shown, steps to protect patients can be delivered inadequately by some, leading to patient safety being put at risk. I believe that the number of safety breaches could be reduced significantly if dentists had the right amount of time to deliver care.
'Time is crucial when consenting patients, delivering treatment, and, importantly, when preparing a safe, hygienic environment for every patient. As dentists, we enter the profession with an aim of helping as many patients as possible, so its vital to make patient safety a top priority.'

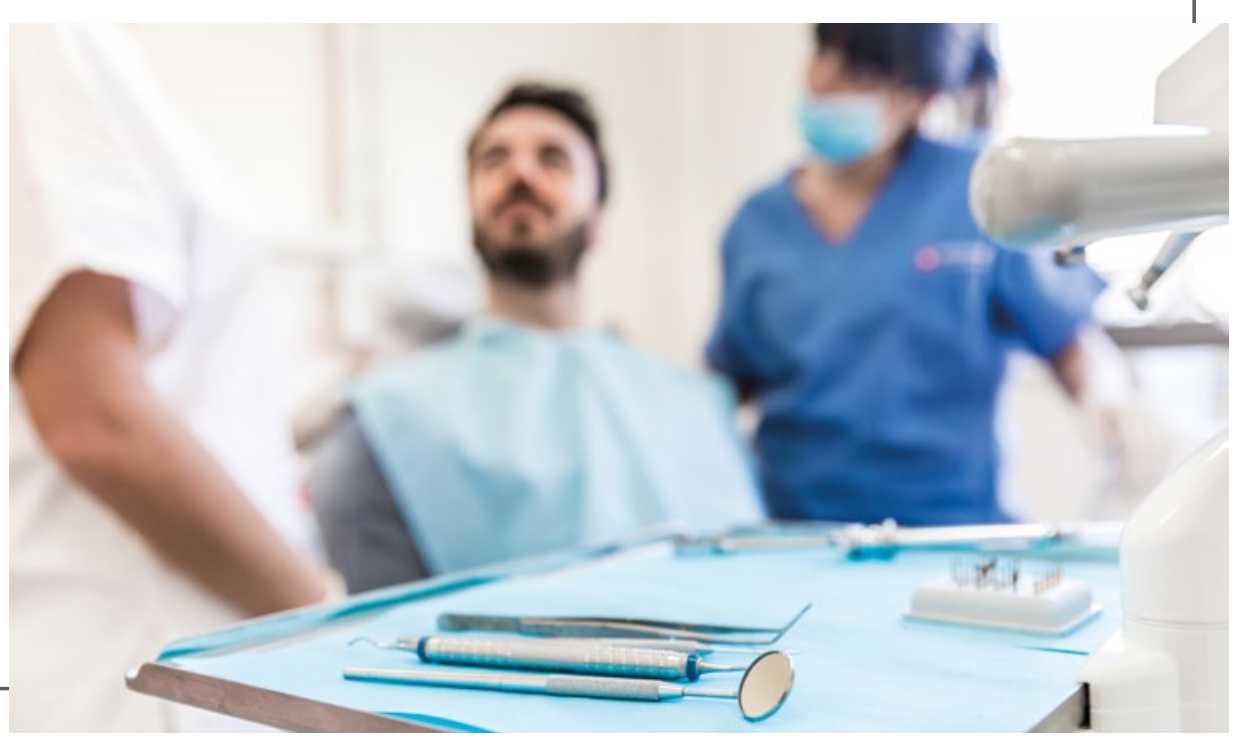

